\title{
GENETICS
}

\section{Titin mutation segregates with hereditary myopathy with respiratory failure}

An inherited mutation in the titin $(T T N)$ gene is associated with hereditary myopathy with early respiratory failure (HMERF), report two new studies published in Brain. Respiratory failure is a rare but progressive complication in some patients with hereditary myopathy. Identification of patients who are prone to this complication would improve symptom management and quality of life.

The study by Anders Oldfors and colleagues examined eight individuals who were from three unrelated families

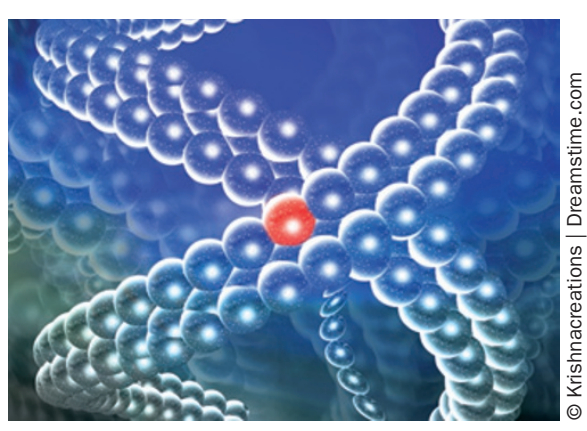

and had adult-onset HMERF. Whole exome sequencing and single nucleotide polymorphism arrays revealed that a mutation in a specific region of TTN, A-band titin, segregated with all affected family members, but was absent in healthy controls. "The affected individuals shared not only the TTN mutation, but also a haplotype on chromosome 2," says Oldfors. In the other study, Patrick Chinnery and colleagues performed genetic analyses such as genome-wide linkage and whole exome sequencing in 31 patients with HMERF. In line with Oldfors' study, the researchers reported that all cases carried a mutation in the A-band region of TTN. Moreover, they showed that this mutation was located within a haplotype on chromosome 2 .

"The giant protein titin is an essential part of the contractile unit of muscle," explains Oldfors. The genetic mutation identified in the two studies alters a highly conserved region of the protein, leading to functional disruption.
In addition to genetic analyses, both studies investigated histopathological and MRI data from mutation carriers, and revealed previously unidentified clinical and pathological features. These characteristics could be helpful for identification of patients who should be analysed for TTN mutations.

A mutation in the TTN kinase domain was previously shown to be associated with HMERF. The new findings reinforce the link with TTN mutations. "Identification of more families carrying TTN mutations will increase the clinical and genetic spectrum of myopathies associated with mutations in A-band titin," says Oldfors.

Iley Ozerlat

\footnotetext{
Original articles Ohlsson, M. et al. Hereditary myopathy with early respiratory failure associated with a mutation in A-band titin. Brain doi:10.1093/brain/aws103 | Pfeffer, G. et al. Titin mutation segregates with hereditary myopathy with early respiratory failure. Brain doi:10.1093/brain/aws102
} 